\title{
Mental health outcomes of mothers who conceived using fertility treatment
}

\author{
Nikolett Raguz', Sheila W McDonald², Amy Metcalfe ${ }^{3}$, Candace O'Quinn ${ }^{1}$ and Suzanne C Tough ${ }^{2,4^{*}}$
}

\begin{abstract}
Objective: To compare the proportion of women with self-reported depression and anxiety symptoms at four months postpartum between mothers of singletons who conceived spontaneously and mothers who conceived with the aid of fertility treatment.

Methods: The sample used for this study was drawn from The "All Our Babies Study", a community-based prospective cohort of 1654 pregnant women who received prenatal care in Calgary, Alberta. This analysis included women utilizing fertility treatment and a randomly selected 1:2 comparison group. The data was collected via three questionnaires, two of which were mailed to the participants during pregnancy and one at four months postpartum. Symptoms of depression and anxiety at four months postpartum were measured using the Edinburg Postnatal Depression Scale and the Spielberger State Anxiety Inventory. Secondary outcomes of parenting morale and perceived stress were also evaluated. Descriptive statistics were used to characterize the population. Chi square tests and in cases of small cell sizes, Fisher Exact Tests were used to assess differences in postpartum mental health symptomatology between groups.

Results: Seventy-six participants (5.9\%) conceived using a form of fertility treatment. At four months postpartum, no significant differences were observed in the proportions reporting excessive depression symptoms (2.6\% vs. 5.3\%, $p=0.50)$, anxiety ( $8.1 \%$ vs. $16.9 \%, p=0.08)$ or high perceived stress scores $(7.9 \%$ vs. $13.3 \%, p=0.23)$. Women who conceived with fertility treatment were less likely to score low on parenting morale compared to women who conceived spontaneously and this was particularly evident in primiparous women (12.5\% vs. $33.8 \%, p=0.01)$. There were no group differences in proportions reporting low parenting morale in multiparous women.

Conclusion: This study suggests that at four months postpartum, the proportion of women who experience elevated symptoms of depression, anxiety or perceived stress do not differ between mothers who conceive using fertility treatment and those who conceive spontaneously. Parenting morale at four months postpartum is significantly lower in primiparous mothers conceiving spontaneously compared to those who conceive with fertility treatment.
\end{abstract}

Keywords: Assisted reproductive technologies, In vitro fertilization, Postpartum depression, Anxiety, Fertility treatment

\section{Introduction}

The development of fertility treatments including fertility enhancing drugs and assisted reproductive technology (ART) has made parenthood possible for countless infertile couples. These couples have often undergone a long period of stress and uncertainty before achieving a successful pregnancy and live birth [1]. In women,

\footnotetext{
* Correspondence: suzanne.tough@albertahealthservices.ca

${ }^{2}$ Department of Pediatrics, University of Calgary, Calgary, Alberta, Canada ${ }^{4}$ Department of Community Health Sciences, University of Calgary, Calgary, Alberta, Canada

Full list of author information is available at the end of the article
}

symptoms of anxiety and depression are common during infertility treatment $[2,3]$.

There is conflicting evidence regarding the psychological state following successful fertility treatment. Some studies have found that symptoms of depression during pregnancy were equivalent among parents of singletons after successful fertility treatment and those conceiving spontaneously $[4,5]$. Some studies suggest that the anxiety level in the population utilizing ART is decreased compared to controls during pregnancy $[4,5]$. However, Hjelmstedt et al. demonstrated increased symptoms of anxiety among

\section{Biomed Central}


those who conceived using ART compared to those who conceived spontaneously [6].

Giving birth after a period of infertility may well be the realization of a long awaited ambition but it might not be as unproblematic as it seems. Prior to the successful pregnancy there may have been periods of waiting and frustration. One can extrapolate that these experiences may foster an idealized and unrealistic image of parenthood. After the birth of the child, unmet expectations and beliefs may result in disenchantment and a climate conducive to mental health issues $[7,8]$.

The information about the postpartum mental health of mothers who have undergone fertility treatments is controversial. In their systematic review, Ross et al. [9] indicate that there may be little or no increased risk of postpartum depression in mothers undergoing ART. However, they caution that most of the data on this topic comes from studies with small sample sizes and lack of appropriate comparison groups. They emphasize the need for further research in this area.

This present study aims to evaluate whether the proportion of women who experienced elevated symptoms of depression and anxiety at four months postpartum differed between women who underwent medical interventions to conceive compared to women who conceived spontaneously. Secondary outcomes of parenting morale and perceived stress were also evaluated between the two groups. Finally, using parity as a stratification variable, we investigated whether there were differences in postpartum mental health between primiparous and multiparous women.

\section{Methods}

A total of 1654 women were recruited to take part in the "All Our Babies" (AOB) study in Calgary Alberta Canada. This was a prospective observational cohort study examining use of prenatal and postpartum services, social support and mental and physical health in pregnancy and the postpartum period.

Information on recruitment, data collection and questionnaires utilized in the $\mathrm{AOB}$ study is described in detail elsewhere $[10,11]$. In brief, women were recruited by posters and postcards in the community, at prenatal clinics in Calgary and by Calgary Laboratory Services (CLS) when they went for prenatal blood group serology testing. Women were then telephoned by a CLS representative to enquire if her name and contact information could be released for research purposes. If the woman agreed, she was contacted by a representative of the research team to tell her about the study and to assess her eligibility and her willingness to participate. In order to enrol in the study, participants had to be less than 24 weeks gestation at the time of recruitment, able to answer a written questionnaire in English and receiving prenatal care in Calgary. Three separate questionnaires were sent to participants during the perinatal period. The first questionnaire was mailed to the participants at 18-24 weeks gestation. A second questionnaire was completed by the participants at between 34 and 36 weeks gestations and a third was completed at four months postpartum. Data was collected from May 2008 to August 2010. Overall, the AOB cohort had an $81 \%$ retention rate. Of the 1654 participants, we excluded individuals with multiple gestation pregnancies $(n=23)$, or who did not complete the first questionnaire (included data on method of conception) and the postpartum questionnaire (included data on postpartum mental health outcomes) $(n=335)$. Our final sample size for analysis was 1296 women.

The first questionnaire collected demographic data, baseline psychosocial and pregnancy data, as well as information on prenatalmental health and experiences of abuse. Information such as age, parity, gravidity, SES, marital status, education, and method of conception was collected. From this data women who utilized medical interventions in order to achieve pregnancy were identified and selected as the study group $(n=76)$. Medical interventions included fertility drugs (Clomid, Serophine, Gonal-F etc.), artificial insemination (AI), intrauterine insemination (IUI), and assisted reproductive technologies (including in vitro fertilization (IVF), intracytoplasmic sperm injection (ICSI), fresh embryo transfer, donor embryo transfer, superovulation/IUI). The control group $(\mathrm{n}=152)$ was randomly selected from the pool of women enrolled in the study $(\mathrm{n}=1220)$ who did not receive medical interventions to achieve pregnancy. As only a small proportion of the cohort conceived with the help of medical interventions, controls were randomly selected from the $\mathrm{AOB}$ cohort on a 2:1 basis using a random number generator.

Pregnancy and postpartum mental health symptoms were measured using standardized scales. Depressive symptoms were assessed using the Edinburgh Postnatal Depression Scale (EPDS). The EPDS is a 10 item self-report scale which was specifically developed as a tool for detecting depression in the perinatal period [12]. It is easily administered and takes about five minutes to complete (Cox et al., [13]). Each item on the scale is given a value between zero and three, with higher scores being consistent with greater depressive symptoms. The total score can range from zero to 30 . A total score of 12 or 13 is indicative of a depressive illness [14] (Sensitivity: 84\%, Specificity: 75\% (Cox et al. [13])). This study utilized a cut-off total score value of 13 or more to identify women with high levels of depressive symptoms, consistent with a clinical diagnosis of major depression [12]. The Spielberger State Anxiety Inventory was employed in this study to evaluate symptoms of anxiety. The inventory contains 20 items which are scored between 1 and 4 
with a higher total score indicating greater anxiety (range 20-80) [15]. An established cut-off score of 40 or more was utilized to categorize women as reporting high levels of anxiety symptoms. To assess stress symptoms the 10item Perceived Stress scale was used. Each item is rated on a five point Likert scales and higher scores indicate greater stress [16]. A cutoff at the $80^{\text {th }}$ percentile was utilized to classify women experiencing high stress symptoms. To evaluate parenting morale, a measure of psychological parental coping resources [17], the Parenting Morale Index was utilized in the postpartum period. This is a ten item questionnaire, with each item being rated on a five point Likert scale. Higher scores reflect better parenting morale [18]. Given no established cut-offs in the literature, we used the $30^{\text {th }}$ percentile of the distribution to classify women as having low levels of parenting morale.

Descriptive statistics were used to characterize the population. Chi square tests and in cases of small cell sizes, Fisher Exact Tests were used to assess differences in postpartum mental health symptomatology between groups. Stratified analysis was used to determine if prenatal and postpartum mental health symptoms differed by parity.

This study was approved by the Conjoint Health Research Ethics Board of the University of Calgary (Ethics ID 20821). Participants provided informed consent at the time of recruitment and were provided copies for their records.

\section{Results}

Of the cohort, $5.9 \%$ of women $(n=76)$ utilized a form of fertility treatment such as ART, fertility enhancing drugs or sperm manipulation techniques to conceive (Table 1). Women who conceived utilizing fertility treatments were significantly older than the population who conceived spontaneously ( 32.9 vs. 30.8 years of age, $\mathrm{p}=0.001$ ) (Table 2). Apart from age, the baseline demographic characteristics of the two groups were similar (Table 2). There were no statistically significant differences between the two groups in terms of previous history of abuse or history of mental disorders (Table 3).

During pregnancy, there were no statistically significant differences in proportions of elevated depression symptoms as scored on the EPDS (Table 3). Nor were there statistically significant differences in the proportions of

Table 1 Type of fertility treatment used $(n=76)$

\begin{tabular}{lc}
\hline Type of intervention & $\mathbf{N}(\%, \mathbf{9 5 \%} \mathbf{C l})$ \\
\hline Fertility-enhancing drugs only & $24(31.6,20.9-42.3)$ \\
Fertility-enhancing drugs and invasive & $27(35.5,24.5-46.5)$ \\
procedure(s) (Al, IUI, IVF, ICSI, embryo transfer, etc.) & \\
$\begin{array}{l}\text { Invasive procedure(s) (AI, IUI, IVF, ICSI, } \\
\text { embryo transfer, etc.) only }\end{array}$ & $25(32.9,22.1-43.7)$ \\
\hline
\end{tabular}

anxiety symptoms as scored on the Spielberger State Anxiety Inventory between the two groups (Table 3 ). However, there was a statistically significant difference between the two groups in terms of Perceived Stress. Women who conceived using fertility treatments were significantly more likely to have lower levels of stress during pregnancy than women who conceived spontaneously $(10.7 \%$ vs. $21.9 \%, \mathrm{p}=0.04)$ (Table 3$)$.

Similar to the prenatal period, at four months postpartum, the proportion of women with elevated depression and anxiety scores were not significantly different between the two groups. In contrast to pregnancy, however, statistically significant differences were not observed in the proportion of women with high perceived stress who conceived with fertility interventions and spontaneously (Table 4). Women who conceived with the aid of fertility treatment were less likely to report low parenting morale ( 19.7 vs. $33.3 \% \mathrm{p}=0.033$ ) (Table 4). Stratified analysis by parity indicated that the difference in parenting morale between the two groups was only for primiparous women. Among primiparous women, women who conceived with fertility treatment were less likely to report low levels of parenting morale compared to women who conceived spontaneously ( $12.5 \%$ vs. $33.8 \%, \mathrm{p}=0.01)$.

\section{Discussion}

The adverse influence of maternal depression on child health and development has been well documented in the literature, impacting global, social, emotional and cognitive development ([19-22], Lyons-Ruth et al. [23-25]). Infertile women have often undergone a long period of stress before achieving a successful pregnancy and symptoms of depression and anxiety are common during infertility treatment [2,3]. Given the importance of maternal mental health on child health and the commonality of anxiety and depression symptoms during fertility treatment we felt that it was important area of research to examine. In this paperwe examined prenatal and postpartum depression, anxiety, and stress symptoms and postpartum parenting morale between women utilizing fertility treatments to conceive and those conceiving spontaneously. Women who conceived using interventions in our sample had lower levels of antenatal stress and higher levels of parenting morale at four months postpartum than those conceiving spontaneously. There were no differences in elevated depression and anxiety symptoms either prenatally or at four months postpartum.

The rate of excessive depression symptoms, consistent with a diagnosis of major clinical depression in the postpartum period, found in this study is somewhat lower than what has been previously reported in the literature. The range cited in the literature for postpartum depression is about $13-19 \%$ [26], whereas in our study the $5.3 \%$ of 
Table 2 Participant demographics

\begin{tabular}{|c|c|c|c|}
\hline Variable & Fertility treatment group $N=76 n(\%)$ & Spontaneous conception group $\mathrm{N}=152 \mathrm{n}(\%)$ & p-value \\
\hline Annual household income & & & 0.068 \\
\hline$<\$ 60,000$ & $5(6.9)$ & $23(15.8)$ & \\
\hline$\geq \$ 60,000$ & $67(93.1)$ & $123(84.2)$ & \\
\hline Education level & & & 0.428 \\
\hline High school or less & $9(11.8)$ & $13(8.6)$ & \\
\hline Some or completed post-secondary & $67(88.2)$ & $139(91.4)$ & \\
\hline Maternal age at delivery & & & $0.002^{*}$ \\
\hline N & 74 & 149 & \\
\hline Mean (Standard deviation) & $33.39(5.11)$ & $31.28(4.47)$ & \\
\hline Time lived in Canada & & & 0.119 \\
\hline Born in Canada/ $\geq 5$ years & $71(94.7)$ & $134(88.2)$ & \\
\hline$<5$ years & $4(5.3)$ & $18(11.8)$ & \\
\hline Ethnicity & & & 0.177 \\
\hline Caucasian & $55(72.4)$ & $122(80.3)$ & \\
\hline Non-caucasian & $21(27.6)$ & $30(19.7)$ & \\
\hline Marital status & & & 0.721 \\
\hline Single, separated, divorced, widowed & $2(2.6)$ & $6(4.0)$ & \\
\hline Married, common-law & $74(97.4)$ & $145(96.0)$ & \\
\hline Parity - birth to a fetus $>24$ weeks & & & 0.100 \\
\hline No previous births & $48(63.2)$ & $78(51.7)$ & \\
\hline Previous birth to a fetus (At least once) & $28(36.8)$ & $73(48.3)$ & \\
\hline Parity category & & & 0.910 \\
\hline Nulliparous & $31(41.3)$ & $58(38.4)$ & \\
\hline Primaparous & $19(25.3)$ & $41(27.2)$ & \\
\hline Multiparous & $25(33.3)$ & $52(34.4)$ & \\
\hline Delivery method & & & 0.063 \\
\hline Vaginal delivery & $52(68.4)$ & $121(79.6)$ & \\
\hline C-section - planned or emergency & $24(31.6)$ & $31(20.4)$ & \\
\hline Preterm birth & & & 0.345 \\
\hline$<37$ weeks of gestation & $2(2.7)$ & $10(6.6)$ & \\
\hline $37-43$ weeks of gestation & $72(97.3)$ & $141(93.4)$ & \\
\hline
\end{tabular}

*Statistically significant.

the control population met the criteria for postpartum depression. This difference may reflect the fact in our study the EPDS was administered at the four month postpartum data collection, which may have missed those who would have met the criteria for postpartum depression before or after that time point. Another possible explanation for this difference might be that a proportion of depressed women, due to the nature of the condition, might not have been capable of or willing to participate in the research. Further differences could also be due to methodological differences across studies in terms of assessment tools, cut-off scores, study designs, and sample characteristics.
Anxiety disorders in the perinatal period are not as well studied as depression, yet both impact birth outcomes and child development; however, the prevalence of anxiety disorders during the postpartum period is higher than postpartum depression [27]. The prevalence of high levels of anxiety symptoms in our study population ranges from $8.1 \%$ to $16.9 \%$ among assisted and spontaneous conceptions respectively. Wenzel et al. [27] found that at eight weeks postpartum, $8.2 \%$ of mothers met the DSM-IV criteria for generalized anxiety disorder and $19.7 \%$ met most of the DSM-IV criteria. Our rate is in line with other literature. However, our measure reflects excessive levels of anxiety symptoms and not anxiety disorder per se. 
Table 3 Maternal prenatal psychosocial health (measured prior to 24 weeks of gestation)

\begin{tabular}{lccc}
\hline Variable & $\begin{array}{c}\text { Fertility } \\
\text { treatment group } \\
\mathrm{N}=76 \mathrm{n}(\%)\end{array}$ & $\begin{array}{c}\text { Spontaneous } \\
\text { conception group } \\
\mathrm{N}=152 \mathrm{n}(\%)\end{array}$ & $\begin{array}{c}\mathrm{p}- \\
\text { value }\end{array}$ \\
\hline Depression & & & \\
\hline
\end{tabular}

\section{Depression}

Depression -

categorized

by 13 cut-off

$\begin{array}{ccc}<13 & 69(90.8) & 140(92.7) \\ \geq 13 & 7(8.2) & 11(7.3)\end{array}$

\section{Anxiety}

Anxiety

$\begin{array}{lll}\text { No } & 63(84.0) & 121(85.2) \\ \text { Yes } & 12(16.0) & 21(14.8)\end{array}$

Stress

Perceived stress score

$-$

$\begin{array}{ccc}\text { Low } & 67(89.3) & 114(78.1) \\ \text { High } & 8(10.7) & 32(21.9) \\ \text { Other } & & \end{array}$

Other

Ever experienced

abuse

\begin{tabular}{|c|c|c|c|}
\hline No & $54(72.0)$ & $99(70.7)$ & \\
\hline Yes & $21(28.0)$ & $41(29.3)$ & \\
\hline $\begin{array}{l}\text { Previous mental } \\
\text { health }\end{array}$ & & & 0.840 \\
\hline $\begin{array}{l}\text { Neither depressed } \\
\text { nor mental disorder }\end{array}$ & $53(69.7)$ & $104(68.4)$ & \\
\hline $\begin{array}{l}\text { Either depressed } \\
\text { or mental disorder }\end{array}$ & $23(30.3)$ & 48 (31.6) & \\
\hline
\end{tabular}

*Statistically significant.

In terms of secondary outcomes, the study detected a significant difference in parenting morale, but not perceived stress in the postpartum period between the two groups. Parenting morale was significantly higher in the group that utilized interventions to conceive. Further analysis showed that this was the case only for primiparous women. A possible explanation for this finding might be that the group with the participants conceiving spontaneously for the first time included women who were not planning a pregnancy. In fact, $18 \%$ of those conceiving spontaneously reported their pregnancy as being mis-timed in comparison to $5.3 \%$ of those using fertility treatments to conceive $(\mathrm{p}=0.008)$. Having an unplanned or suboptimally timed pregnancy may influence preparedness and eagerness to parent, hence influencing enthusiasm for the parenting role, operationalized in this study as parenting morale.

Interestingly, this study found a difference in perceived stress levels between the two groups antenatally but not in the postpartum period. One may speculate that this
Table 4 Postpartum psychosocial health

\begin{tabular}{|c|c|c|c|}
\hline Variable & $\begin{array}{c}\text { Fertility } \\
\text { treatment group } \\
\mathrm{N}=76 \mathrm{n}(\%)\end{array}$ & $\begin{array}{c}\text { Spontaneous } \\
\text { conception group } \\
\mathrm{N}=152 \mathrm{n}(\%)\end{array}$ & p-value \\
\hline \multicolumn{4}{|l|}{ Parenting morale } \\
\hline $\begin{array}{l}\text { Parenting morale } \\
\text { score }\end{array}$ & & & $0.033^{*}$ \\
\hline Low $(<37)$ & $15(19.7)$ & $50(33.3)$ & \\
\hline High ( $\geq 37)$ & $61(80.3)$ & $100(66.7)$ & \\
\hline \multicolumn{4}{|l|}{ Depression } \\
\hline $\begin{array}{l}\text { Depression - } \\
\text { categorized } \\
\text { by } 13 \text { cut-off }\end{array}$ & & & 0.502 \\
\hline$<13$ & $74(97.4)$ & $144(94.7)$ & \\
\hline$\geq 13$ & $2(2.6)$ & $8(5.3)$ & \\
\hline \multicolumn{4}{|l|}{ Anxiety } \\
\hline $\begin{array}{l}\text { Anxiety at time } \\
3 \text { - categorized }\end{array}$ & & & 0.075 \\
\hline No & 68 (91.9) & $123(83.1)$ & \\
\hline Yes & $6(8.1)$ & $25(16.9)$ & \\
\hline \multicolumn{4}{|l|}{ Stress } \\
\hline Perceived stress score & & & 0.226 \\
\hline Low & $70(92.1)$ & $130(86.7)$ & \\
\hline High & $6(7.9)$ & $20(13.3)$ & \\
\hline
\end{tabular}

*Statistically significant.

lower level of antenatal stress in the fertility treatment group may be due to a sense of relief following successfully achieving a long awaited pregnancy. Further research following the trajectory of stress symptoms across time between the two groups, as well as delineation of factors impacting changes in stress would be beneficial.

There are limitations to our study. The data measured in this study were obtained from maternal self-report and this may introduce error. Also, our study population may not be representative of the general pregnant population. The methods we utilized to recruit participants may have selected a highly motivated group, as many of the participants were recruited via posters and postcards. Our questionnaires, although fairly straightforward, were rather lengthy. This might have resulted in a population with a higher education to be more likely to complete the questionnaire. However in comparison with both local and provincial statistics, we have shown that the participants are representative of women giving birth in an urban Canadian centre [10]. Our study was also limited to those participants who could answer a questionnaire in English. This may be a limitation as Sword et al. [28] showed in a Canadian sample that foreign born women are at a higher risk of postpartum depression in comparison to Canadian born women. Furthermore, our study did not examine the effect of mode of conception on rates of high levels of postpartum maternal distress while controlling 
for other known risk factors for poor mental health in the postpartum period, such as antenatal distress and history of adverse experiences. Another limitation of this study is that different forms of fertility treatment were combined in the analysis and perhaps there is a differential impact on mental health between the different types of treatment. Our sample size was too small for multivariable modelling, therefore further research with larger sample sizes is warranted.

\section{Conclusion}

This study suggests that during pregnancy, there were no statistically significant differences in the proportions of high depression and anxiety symptoms between women conceiving with fertility treatments and those conceiving spontaneously. Women who conceived using fertility treatments were significantly more likely to have lower levels of antepartum stress than women who conceived spontaneously. At four months postpartum, mothers who conceive with fertility treatment do not differ from those who conceived spontaneously in the proportion of elevated depression, anxiety or perceived stress symptoms. First time mothers utilizing fertility treatments to conceive were statistically significantly less likely to report low parenting morale at four months postpartum.

\section{Competing interests}

The authors declare that they have no competing interests.

\section{Authors' contributions}

$\mathrm{SCT}$ is responsible for the overall integrity, progress and timely completion of the $A O B$ study and participated in the design of the study. NLR drafted the manuscript, contributed to the development of the research question, study design and contributed to the interpretation of study results. SWM performed data linkage, and conducted all statistical analyses. NLR, SWM, AM, CO participated in meetings related to study issues and progress as needed. NLR, SWM, AM, CO and SCT were involved in the study design and providing advice on methodological issues. All authors have read and approved the final manuscript.

\section{Acknowledgments}

We are exceptionally grateful to the participants involved in the All Our Babies cohort, and to the All Our Babies staff and research team. We are tremendously appreciative of the investigators, co-ordinators, research assistants, graduate and undergraduate students, volunteers, clerical staff and managers. Alberta Innovates - Health Solutions, (formerly the Alberta Heritage Foundation for Medical Research), Three Cheers for the Early Years, Alberta Health Services and the Alberta Children's Hospital Foundation have provided support for the All Our Babies study. The University of Calgary has provided trainee salary support. Amy Metcalfe holds a Canadian Institutes of Health Research fellowship award. Sheila McDonald holds a post-doctoral fellowship award from the Alberta Centre for Child Family and Youth. Suzanne Tough holds a Health Scholar Award from Alberta Innovates Health Solutions.

We would like to gratefully acknowledge Calgary Laboratory Service for their support of recruitment, sample collection, and specimen banking.

\section{Author details}

${ }^{1}$ Department of Obstetrics and Gynecology, University of Calgary, Calgary, Alberta, Canada. ²Department of Pediatrics, University of Calgary, Calgary, Alberta, Canada. ${ }^{3}$ Department of Obstetrics and Gynecology, University of British Columbia, Vancouver, British Columbia, Canada. ${ }^{4}$ Department of Community Health Sciences, University of Calgary, Calgary, Alberta, Canada.
Received: 14 June 2013 Accepted: 21 February 2014

Published: 28 February 2014

\section{References}

1. Tarabusi M, Volpe A, Facchinetti F: Psychological group support attenuates distress of waiting in couples scheduled for assisted reproduction. J Psychosom Obstet Gynaecol 2004, 25(3/4):273-279.

2. Beaurepaire J, Jones M, Thiering P, Saunders D, Tennant C: Psychosocial adjustment to infertility and its treatment: male and female responses at different stages of IVF/ET treatment. J Psychosom Res 1994, 38(3):229-240.

3. Souter VL, Hopton JL, Penney GC, Templeton AA: Survey of psychological health in women with infertility. Psychosom Obstet Gynecol 2002, 23(1):41-49.

4. Klock SC, Greenfeld DA: Psychological status of in vitro fertilization patients during pregnancy: a longitudinal study. Fertil Steril 2000, 73(6):1159-1164.

5. Repokari L, Punamaki RL, Poikkeus P, Vilska S, Unkila-Kallio L, Sinkkonen J, Almqvist F, Tiitinen A, Tulppala M: The impact of successful assisted reproduction treatment on female and male mental health during transition to parenthood: a prospective controlled study. Hum Reprod 2005, 20(11):3238-3247.

6. Hjelmstedt A, Widstrom AM, Wramsby H, Matthiesen AS, Collins A: Personality factors and emotional responses to pregnancy among IVF couples in early pregnancy: a comparative study. Acta Obstet Gynecol Scand 2003, 82(2):152-161.

7. Fisher JRW, Hammarberg K, Baker GHW: Antenatal mood and fetal attachment after assisted conception. Fertil Steril 2008, 89(5):1103-1112.

8. Meager I, Milgrom J: Group treatment for postpartum depression: a pilot study. Aust N Z J Psychiatry 1996, 30:852-860.

9. Ross LE, McQueen K, Vigod S, Dennis CL: Risk for postpartum depression associated with assisted reproductive technologies and multiple births: a systematic review. Hum Reprod 2011, 17(1):96-106.

10. McDonald SW, Lyon AW, Benzies KM, McNeil DA, Lye SJ, Dolan SM, Pennell CE, Bocking AD, Tough SC: The all our babies cohort: design, methods and participant characteristics. BMC Pregnancy Childbirth 2013, 13(Suppl 1):S2.

11. Gracie SK, Lyon AW, Kehler HL, Pennell CE, Dolan SM, McNeil DA, Siever JE, McDonald SW, Bocking AD, Lye SJ, Hegadoren KM, Olson DM, Tough SC: All our babies cohort study: recruitment of a cohort to predict women at risk of preterm birth through the examination of gene expression profiles and the environment. BMC Pregnancy Childbirth 2010, 10:87.

12. Cox JL, Holden JM, Sagovsky R: Detection of postnatal depression. Development of the 10-item Edinburgh postnatal depression scale. Br J Psychiatry 1987, 150:782-786.

13. Cox JL, Holden JM: Perinatal Psychiatry: Use and Misuse of the Edinburgh Postnatal Depression Scale. London: Gaskell; 1994

14. Sheard C, Cox S, Oates M, Ndukwe G, Glazebrook C: Impact of a multiple, IVF birth on post-partum mental health: a composite analysis. Hum Reprod 2007, 22(7):2058-2065.

15. Spielberger CD, Gorusch RL, Lushene RE: Manual for the state-trait anxiety inventory. Consulting psychologist press, Palo Alto, CA, USA. J Affect Disord 1970, 39(| 996):185-189.

16. Cohen S, Kamarck T, Mermelstein R: A global measure of perceived stress. J Health Soc Behav 1983, 24:385-396.

17. Benzies KM, Trute B, Worthington C, Reddon J, Keown L, Moore M: Assessing psychological well-being in mothers of children with disability: evaluation of the parenting morale index and family impact of childhood disability scale. J Pediatr Psychol 2011, 36(5):506-516.

18. Trute B, Hiebert-Murphy D: Predicting family adjustment and parenting stress in childhood disability services using brief assessment tools. J Intellect Dev Disabil 2005, 30(217):225.

19. Kingston D, Tough S, Whitfield H: Prenatal and postpartum maternal psychological distress and infant development: a systematic review. Child Psychiatry Hum Dev 2012, 43(5):683-714.

20. Avan B, Richter LM, Ramchandani PG, Norris SA, Stein A: Maternal postnatal depression and children's growth and behaviour during the early years of life: exploring the interaction between physical and mental health. Arch Dis Child 2010, 95(9):690-695.

21. Tough SC, Siever JE, Leew S, Johnston DW, Benzies K, Clark D: Maternal mental health predicts risk of developmental problems at 3 years of age: follow up of a community based trial. BMC Pregnancy Childbirth 2008, 8:16.

22. Grace SL, Evindar A, Stewart DE: The effect of postpartum depression on child cognitive development and behavior: a review and critical analysis of the literature. Arch Womens Ment Health 2003, 6(4):263-274. 
23. Beck $C T$ : The effects of postpartum depression on child development: a meta-analysis. Arch Psychiatr Nurs 1998, 12(1):12-20.

24. Murray L, Cooper PJ: Postpartum depression and child development. Psychol Med 1997, 27(2):253-260.

25. Lyons-Ruth $K$, Wolfe R, Lyubchik A: Depression and the parenting of young children: making the case for early preventive mental health services. Harv Rev Psychiatr 2000, 8(3):148-153.

26. O'Hara MW, McCabe JE: Postpartum depression: current status and future directions. Annu Rev Clin Psychol 2013, 9:6.1-6.30.

27. Wenzel A, Haugen EN, Jackson LC, Brendle JR: Anxiety symptoms and disorders at eight weeks postpartum. J Anxiety Disord 2005, 19(3):295-311.

28. Sword W, Watt S, Krueger P: Postpartum health, service needs, and access to care experiences of immigrant and Canadian-born women. $J$ Obstet Gynecol Neonatal Nurs 2006, 35:717-727.

doi:10.1186/1742-4755-11-19

Cite this article as: Raguz et al: Mental health outcomes of mothers who conceived using fertility treatment. Reproductive Health 2014 11:19.

\section{Submit your next manuscript to BioMed Central and take full advantage of:}

- Convenient online submission

- Thorough peer review

- No space constraints or color figure charges

- Immediate publication on acceptance

- Inclusion in PubMed, CAS, Scopus and Google Scholar

- Research which is freely available for redistribution 